\section{Upping the impact: to (not quite!) infinity and beyond}

\author{
Andrew Bush, lan Pavord
}

The year 2014 has been a mixed one for Thorax. Sadly, our Golfing Editor in Chief (EIC) has surrendered his trophy (see Airwaves, September). However, this

\footnotetext{
${ }^{1}$ National Heart and Lung Institute, Imperial College, London, UK; ${ }^{2}$ Nuffield Department of Medicine, University of Oxford, Oxford, UK
}

Correspondence to Professor Andrew Bush, National Heart and Lung Institute, Imperial College, London, SW3 6NP, UK; a.bush@imperial.ac.uk means he is now able to focus more on the Journal in the brief intervals between Bullingdon club meetings. On a better note, we are very happy to announce our new impact factor of 8.562, which has risen to the highest in Thorax history. Chief credit is to the excellence of the manuscripts you have submitted, the editorial team and reviewers for their skill in picking out the best ones from a rich field of choices and the support of the $B M J$ team. We are still chasing the Blue Journal but we also still have a good sized gap over the rest of the field. Wherever you are in the world, send us your best manuscripts; we are a truly international journal and take good work from all round the globe.

\section{Competing interests None.}

Provenance and peer review Commissioned; internally peer reviewed.

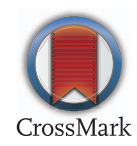

To cite Bush A, Pavord I. Thorax 2014;69:890.

Thorax 2014;69:890.

doi:10.1136/thoraxjnl-2014-206132 